\title{
Suplementação de metionina e/ou lisina em rações para juvenis de tambaqui (Colossoma macropomum Cuvier, 1818)
}

\author{
Lian V. BRANDÃOํㅗㄹ Manoel PEREIRA-FILHO², Sérgio Fonseca GUIMARÃES³, Flávio A. L. da FONSECA ${ }^{4}$ \\ RESUMO \\ Foi avaliado o efeito da redução dos níveis de proteína e a suplementação de metionina e/ou lisina em rações sobre a excreção \\ de amônia em juvenis de tambaqui (Colossoma macropomum). O experimento foi realizado em delineamento inteiramente \\ casualizado com esquema fatorial de duas entradas: 2 níveis protéicos (25 e 20\%) e 4 níveis de inclusão de aminoácidos: a) \\ $0 \%$ de suplementação, b) DL-Metionina (3\% da PB), c) L-lisina (5\% da PB) e d) Dl-Metionina (3\% da PB) + L-lisina (5\% \\ da PB), com duração de 55 dias. A coleta de água das unidades experimentais ocorreu em três momentos $\left(1^{\circ}\right.$ dia, $27^{\circ}$ dia e \\ $55^{\circ}$ dia) durante o período experimental. Nestes dias, foram realizadas 3 coletas de amostras de água para análise de amônia \\ de cada unidade experimental (08:00 , 14:00 e 20:00 horas). Os dados de excreção de amônia foram analisados por ANOVA \\ com medidas repetidas no tempo a 5\% do nível de significância. A redução em 5\% do nível de proteína na dieta gerou \\ uma diminuição de $28,4 \%$ na excreção de amônia. Contudo, a suplementação de lisina e metionina não influenciaram esta \\ diminuição.
}

PalaVRaS-ChaVE: Amônia, Lisina, Metionina, Proteína, Tambaqui.

\section{Reduction of protein levels and methionine and/or lysine supplementation in diets and their effects in total ammonia nitrogen excretion of tambaqui juveniles (Colossoma macropomum Cuvier, 1818)}

\begin{abstract}
It was evaluated the effect of the reduction of crude protein level (CP) and the lysine and/or methionine supplementation in total ammonia nitrogen excretion on tambaqui (Colossoma macropomum) juveniles. The experiment developed in a factorial and randomized design with two levels of protein contents (20\% and $25 \% \mathrm{CP})$ and four levels of amino acid supplementation: a) Dl-methionine ( $0 \%$ of CP) and L-lysine ( $0 \%$ of CP), b) Dl-methionine (3\% of CP), c) L-lysine ( $5 \%$ of CP), d) Dl-methionine $\left(3 \%\right.$ of CP) + L-lysine $\left(5 \%\right.$ of CP), during 55 days. The water sampling from experimental units was done at 3 moments $\left(1^{0}\right.$ day, $27^{0}$ day e $55^{\circ}$ day). In these days, 3 samples of each experimental unit were collected in elapsing of the time (08:00 a.m., 02:00 p.m. and 08:00 p.m.). The ammonia excretion data were analysed by repeated-measures ANOVA ( $p>0,05)$ with time as within effect. The reduction of $5 \%$ in diet protein, decreased in $28,4 \%$ total ammonia excretion decreased, however, the lysine and methionine supplementation did not influenced this factor.
\end{abstract}

KEY WORDS: Methionine, Lysine, Tambaqui, Protein, Ammonia.

\footnotetext{
1 Instituto Nacional de Pesquisas da Amazônia - INPA, CP 478, Manaus, AM. E-mail: lianpesca@yahoo.com.br

2 Instituto Nacional de Pesquisas da Amazônia - INPA. Manaus-AM. E-mail: pmanoel@inpa.gov.br

${ }^{3}$ Instituto Nacional de Pesquisas da Amazônia - INPA. Manaus-AM. E-mail: sfg@inpa.gov.br

${ }^{4}$ Instituto Nacional de Pesquisas da Amazônia - INPA. Manaus-AM. E-mail: guto@inpa.gov.br
} 


\section{INTRODUÇÃO}

Na região Norte do Brasil, o tambaqui é a espécie de maior destaque e importância comercial. Este fator, bem como o seu desempenho em ambiente de cultivo tem estimulado pesquisas com o objetivo de aprimorar a sua tecnologia de produção (Melo et al., 2001; Chagas et al., 2003; Izel et al., 2004).

A rápida expansão da piscicultura está diretamente ligada a sua rentabilidade, a qual é otimizada ao adotar sistemas que utilizam rações balanceadas e de boa qualidade, por permitirem o aumento da produtividade com menor impacto ambiental. De acordo com Thoman et al. (1999) a otimização dos níveis protéicos da dieta juntamente com o aumento da retenção de nutrientes pelos peixes, poderia diminuir as perdas de nitrogênio e os custos de produção.

No efluente de piscicultura, o nitrogênio é considerado a principal fonte de poluição, podendo resultar em elevada eutrofização, produzindo compostos tóxicos aos peixes (English et al., 1993) e, no caso de predomínio de cianobactérias, pode prejudicar as características organolépticas da carcaça dos peixes por provocar offflavor (Van Der Ploeg \& Tucker, 1994). Dos compostos nitrogenados, a amônia $\left(\mathrm{NH}_{3}\right)$ é o principal produto de excreção dos peixes (Westers, 2001), resultante do catabolismo das proteínas. No caso do tambaqui, representa aproximadamente 93,7\% do nitrogênio excretado (IsminoOrbe et al., 2003).

As taxas de excreção de amônia em teleósteos estão diretamente relacionadas à ingestão de proteína e nitrogênio contidos na dieta (Kaushik \& Cowey, 1990). O valor biológico de uma proteína varia com a composição dos aminoácidos e suas respectivas disponibilidades (Ahmed \& Khan, 2004). A deficiência ou a baixa disponibilidade de aminoácidos essenciais leva à baixa utilização da proteína e, conseqüentemente ao menor crescimento e diminuição da eficiência alimentar dos peixes (Pezzato, 1997).

Diversos estudos têm estimulado pesquisas sobre fontes alternativas de proteínas, basicamente ingredientes vegetais (Carter \& Hauler, 2000; Alceste \& Jory, 2000). Os ingredientes de origem vegetal têm sido utilizados em substituição à farinha de peixe, pelo menor custo e disponibilidade no mercado. Entre os ingredientes de origem vegetal, o farelo de soja é a fonte mais utilizada para a elaboração de raçōes para organismos aquáticos, pelo baixo custo e elevado valor nutricional (Furuya et al., 2004a). Porém, pode apresentar fatores antinutricionais, como inibidores de protease e amilase que interferem na digestibilidade, absorção ou utilização de ingredientes, além da limitação em aminoácidos, especialmente a metionina (Storebakken et al., 2000), geralmente necessitando de suplementação quando utilizados em rações para organismos aquáticos (Furuya et al., 2004b).
Por outro lado, há evidências, de que o uso excessivo de aminoácidos sintéticos nas rações de baixo teor protéico pode não garante a mesma eficiência de utilização dos aminoácidos oriundos de proteína intacta (NRC, 1993; Dabrowski \& Guderley, 2002).

Diminuir a concentração de proteína da ração concomitantemente a suplementação de aminoácidos limitantes pode ser uma estratégia para reduzir o teor de nitrogênio excretado no meio ambiente, sem prejudicar o desempenho dos peixes (Rollin et al., 2003; Yamamoto et al., 2005)

Segundo Ruchimat et al. (1997), a metionina é um aminoácido essencial, sendo imprescindível para o crescimento normal do organismo, já que ela não pode ser sintetizada no corpo, sendo requerida para síntese protéica e vários outros processos metabólicos. De acordo com o NRC (1993), em raçôes para peixes onívoros, os aminoácidos sulfurados, como por exemplo, a metionina, deve estar presente na proporção de $3 \%$ da proteína da ração.

Outro aminoácido essencial é a lisina, que está presente em elevados níveis no tecido muscular dos peixes, sendo exigida em grande quantidade na ração (Furuya et al., 2004b), tendo em vista que esta é usualmente limitada em fontes de proteína vegetal, como por exemplo, fubá de milho, farelo de gergelim e gergelim. Para espécies herbívoras e onívoras, o teor de lisina na ração é de aproximadamente $1,5 \%$ ou aproximadamente $5 \%$ da proteína da ração (NRC, 1993). A lisina junto com a metionina é a precursora da carnitina que é requerida para o transporte intracelular de ácidos graxos de cadeia longa no interior da célula. (Walton et al., 1984).

Deste modo, este trabalho teve por objetivo verificar o efeito da redução do teor de proteína na ração, através de um reforço compensatório, nos níveis de metionina e/ou lisina, sobre a excreção de nitrogênio $\left(\mathrm{NH}_{4}^{+}\right)$de juvenis de tambaqui cultivados.

\section{MATERIAL E MÉTODOS}

O estudo foi realizado no Instituto Nacional de Pesquisas da Amazônia - INPA, Manaus-AM, na Coordenação de Pesquisas em Aqüicultura - CPAQ.

O experimento foi conduzido em um esquema fatorial $2 \mathrm{x}$ 4, perfazendo um total de 8 tratamentos em triplicata. Foram testados dois níveis de proteína bruta na ração $(25 \%, 20 \%)$, combinados com quatro níveis de inclusão de aminoácidos essenciais a) SS: metionina ( $0 \%$ da PB da ração) + lisina ( $0 \%$ da PB da ração); b) Met: metionina (3\% da PB da ração) + lisina ( $0 \%$ da PB da ração); c) Lis: metionina ( $0 \%$ da PB da ração) + lisina ( $5 \%$ da PB da ração) e d) M + L: metionina (3\% da $\mathrm{PB}$ da ração) + lisina ( $5 \%$ da PB da ração). Foram utilizados juvenis de tambaqui, com peso médio de $64,5 \mathrm{~g} \pm 1,06$, 
provenientes de produtor particular. Os animais experimentais foram medidos $(\mathrm{cm})$, pesados $(\mathrm{g})$ e posteriormente distribuídos em 24 cones com capacidade de 120 litros, na densidade de 14 indivíduos por unidade experimental, totalizando 336 exemplares.

O experimento teve duração de 55 dias. De acordo com a metodologia utilizada nesta coordenação, durante este período foram pré-determinadas 3 datas para a coleta de água das unidades experimentais $\left(1^{\circ} \mathrm{dia}, 27^{\circ} \mathrm{dia}\right.$ e $\left.55^{\circ} \mathrm{dia}\right)$. Nesses dias foram realizadas 3 coletas a meia profundidade no centro de cada tanque e no decorrer do tempo (08:00, 14:00 e 20:00 horas). A renovação de água foi interrompida antes da primeira coleta e religada somente após a última coleta do dia. A alimentação permaneceu constante (duas vezes ao dia: 09:00 e 16:00 horas, até saciedade aparente). Neste trabalho, considerou-se saciedade aparente quando não eram mais observadas capturas e regurgitação dos grânulos, evitando-se sobras. Após a alimentação, foi feita uma descarga de água em cada unidade experimental para retirar quaisquer sobras de ração existentes.

As análises para determinação da amônia total das amostras foram realizadas imediatamente após cada coleta. Para obtenção destes dados foi utilizado o método da fotometria com uso de um fotômetro MERCK, modelo NOVA 60.

$\mathrm{O}$ experimento foi conduzido em um esquema fatorial $2 \mathrm{x}$ 4, perfazendo um total de 8 tratamentos em triplicata. Foram testados dois níveis de proteína bruta na ração $(25 \%, 20 \%)$, combinados com quatro níveis de inclusão de aminoácidos essenciais a) SS: metionina ( $0 \%$ da PB da ração) + lisina ( $0 \%$ da $\mathrm{PB}$ da ração); b) Met: metionina (3\% da PB da ração) + lisina ( $0 \%$ da PB da ração); c) Lis: metionina ( $0 \%$ da PB da ração) + lisina (5\% da PB da ração) e d) $\mathrm{M}+\mathrm{L}$ : metionina (3\% da PB da ração) + lisina (5\% da PB da ração).

As fontes protéicas de origem vegetal escolhidas para compor as rações foram o farelo de soja e a farinha de glúten de milho. Foram formuladas oito raçôes isocalóricas, das quais, quatro raçôes continham $25 \% \mathrm{~PB}$ e as outras quatro raçôes, 20\% PB (Tabela 01).
Todos os ingredientes foram homogeneizados e umedecidos e as rações foram peletizadas em prensa elétrica, desidratadas por 24 horas sob circulador de ar e armazenadas em sacos de polietileno em freezer $\left(-20^{\circ} \mathrm{C}\right)$ até o momento do arraçoamento.

As análises laboratoriais dos ingredientes e das rações foram determinadas segundo metodologia proposta pela AOAC. (1995). A energia bruta (kcal.100g $\left.{ }^{-1}\right)$ foi calculada utilizando os índices de 5,64 para a proteína bruta, 9,44 para os lipídios e 4,11 para os carboidratos, segundo NRC (1993). Os carboidratos foram obtidos por diferença.

Os dados de excreção de amônia foram analisados por ANOVA com medidas repetidas no tempo a 5\% do nível de significância. Para determinação da esfericidade foi utilizado o teste multivariado de Greenhouse \& Geisser (1959) para ajuste e correção dos graus de liberdade e valores de $\mathrm{p}$.

\section{RESULTADO E DISCUSSÃO}

As taxas médias de amônia total apresentaram diferença ( $\mathrm{p}$ $<0,05)$ para os dois níveis de proteína e para a interação destes níveis protéicos com o horário (Figura 1). Pode-se observar que após 12 horas, a concentração média de amônia total nos tratamentos contendo $25 \%$ de proteína bruta foi de 0,88 mg. $\mathrm{L}^{-1}$, enquanto que para os tratamentos contendo $20 \%$ de proteína bruta a concentração média de amônia total foi de 0,63 mg. $\mathrm{L}^{-1}$, ou seja, uma redução de $28,40 \%$.

Neste estudo, dietas com nível mais alto de proteína bruta resultaram em maiores taxas de amônia total na água, o que está de acordo com os resultados encontrados por outros autores (Rychly, 1980; Chakraborty et al., 1992). Analisando-se estes resultados pode-se observar que os mesmos foram similares aos encontrados por Cheng et al. (2003) com truta arco-íris, Oncorhynchus mykiss, que concluíram que ao diminuir a quantidade de proteína bruta de $42 \%$ para $37 \%$, a excreção total de amônia decaiu em $12 \%$. Esses resultados corroboram a afirmação de que as taxas de excreção de amônia em teleósteos estão diretamente relacionadas à ingestão de

Tabela 1 - Composição percentual e composição centesimal das rações experimentais

\begin{tabular}{lcccccccc}
\hline & \multicolumn{1}{c}{ Rações } \\
\cline { 2 - 9 } Ingredientes & \multicolumn{1}{c}{ 25\% PB } & \multicolumn{4}{c}{$20 \%$ PB } \\
\cline { 2 - 9 } & & SS & Met & Lis & M + L & SS & Met & Lis \\
\hline Farelo de Soja & 19 & 18,6 & 18,6 & 16,3 & 17,2 & 13,8 & 13,8 & 13,1 \\
Fubá de milho & 42,7 & 42,9 & 43,2 & 43,5 & 46,9 & 48,1 & 48,1 & 48,7 \\
Farelo de Trigo & 20,5 & 20,9 & 20,9 & 21,8 & 28 & 28,5 & 28,5 & 28,5 \\
Protenose (gluten de milho) & 13 & 12 & 11,1 & 11,4 & 3,1 & 3,7 & 3,7 & 3,1 \\
\hline
\end{tabular}


Tabela 1 - Continuação

\begin{tabular}{|c|c|c|c|c|c|c|c|c|}
\hline \multirow{3}{*}{ Ingredientes } & \multicolumn{8}{|c|}{ Rações } \\
\hline & \multicolumn{4}{|c|}{$25 \%$ PB } & \multicolumn{4}{|c|}{$20 \%$ PB } \\
\hline & SS & Met & Lis & $M+L$ & SS & Met & Lis & $M+L$ \\
\hline Premix* & 0,8 & 0,8 & 0,8 & 0,8 & 0,8 & 0,8 & 0,8 & 0,8 \\
\hline DI - Metionina & - & 0,8 & - & 0,8 & - & 0,8 & - & 0,8 \\
\hline$L-$ Lisina & - & - & 1,4 & 1,4 & - & - & 1,4 & 1,4 \\
\hline Fibra de soja & 4 & 4 & 4 & 4 & 4 & 4 & 4 & 4 \\
\hline \multicolumn{9}{|c|}{ Composição centesimal (\%) } \\
\hline Umidade & 7,1 & 7,1 & 5,6 & 10,1 & 6,8 & 8,6 & 6,8 & 7,7 \\
\hline Proteína bruta & 20,2 & 20,0 & 20,0 & 20,2 & 25,8 & 25,5 & 25,0 & 25,1 \\
\hline Extrato etéreo & 2,3 & 2,3 & 2,6 & 2,6 & 2,9 & 2,8 & 2,7 & 2,9 \\
\hline Fibra bruta & 5,4 & 5,4 & 5,4 & 5,3 & 5,9 & 5,7 & 5,7 & 5,7 \\
\hline Extratos não nitrogenados & 61,2 & 61 & 62,5 & 58,1 & 54,9 & 53,7 & 54,5 & 55,3 \\
\hline Cinzas & 3,8 & 3,5 & 3,9 & 3,7 & 3,7 & 3,7 & 5,3 & 3,3 \\
\hline Energia Bruta(kcal/100g) & 302,4 & 299,8 & 298,1 & 297 & 300,3 & 301 & 299,7 & 297,7 \\
\hline EB : PB & 14,97 & 14,98 & 14,90 & 14,7 & 11,63 & 11,80 & 11,98 & 11,86 \\
\hline
\end{tabular}

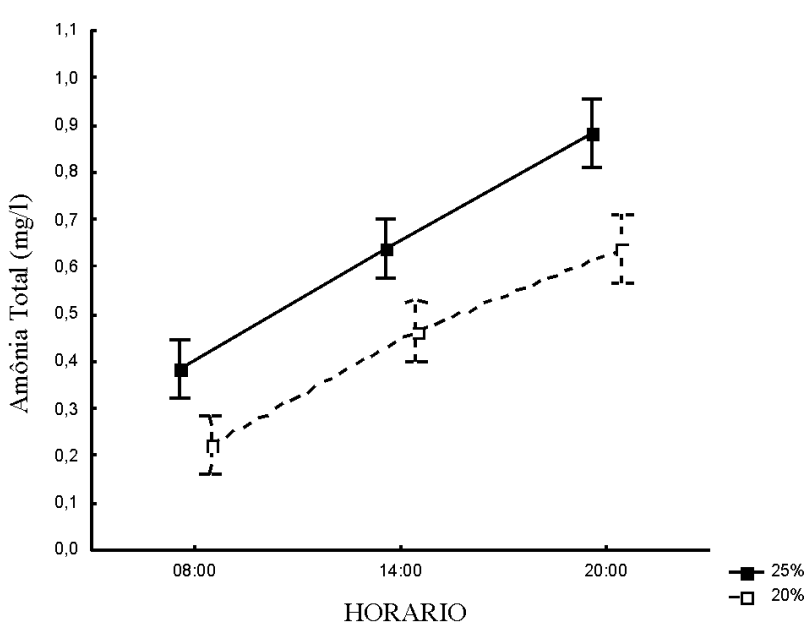

Figura 1 - Relação: Concentração de Amônia total $\left(\mathrm{NH}_{4}^{+}\right)$x Horário de coleta

proteína e nitrogênio contidos na dieta (Kaushik \& Cowey, 1990).

Viola \& Lahav (1991) reportam que ao alimentar carpa comum, Cyprinus carpio, com dietas contendo $25 \%$ de PB suplementada com $0,5 \%$ de lisina, obtiveram reduçóes de excreção de amônia e fósforo total por unidade de ganho de peso de $20 \%$ e $10 \%$ respectivamente, quando comparado com os peixes alimentados com ração contendo $30 \%$ de PB. Viola et al. (1992) enfatizam que a redução da proteína bruta da dieta de $30 \%$ para $25 \%$ suplementada com $0,5 \%$ de lisina mais $0,3 \%$ de metionina, para carpa comum, reduz a excreção de nitrogênio em $20 \%$.

Neste trabalho as suplementações das rações com lisina e/ ou metionina não geraram diferenças significativas $(p>0,05)$ na concentração de amônia total na água (Figura 2). Esse resultado é explicado, em parte, pelo baixo número diário de arraçoamentos utilizado neste experimento. Isso ocorre, uma vez que uma maior freqüência alimentar diária poderia ter proporcionado a melhor utilização dos aminoácidos, conseqüentemente uma melhor eficiência protéica, evitando assim, o aumento de seu catabolismo (Tantikitti \& March, 1995; Rodehutscord et al., 2000; Aoki et al., 2001).

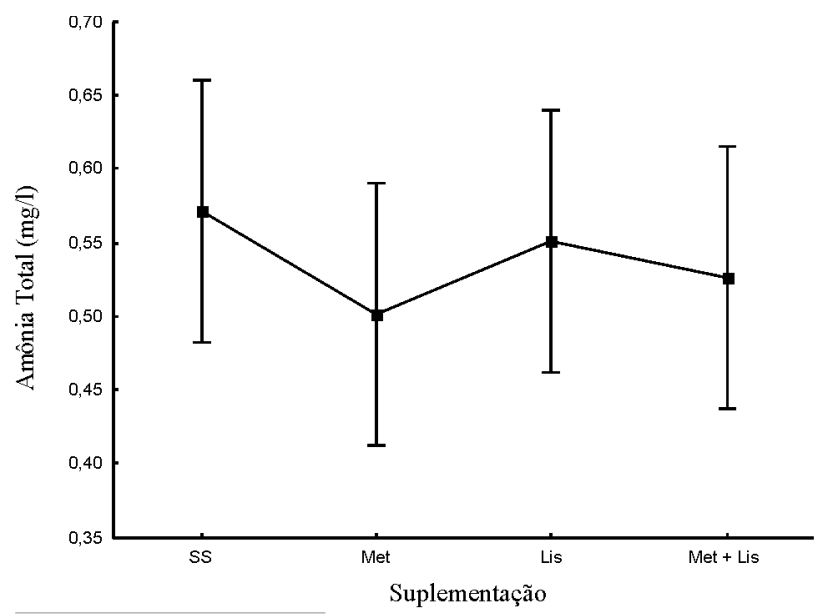

Figura 2 - Relação Concentração de Amônia Total $\left(\mathrm{NH}_{4}^{+}\right)$x Suplementação de aminoácidos 


\section{CONCLUSÕES}

A concentração de amônia foi reduzida com a diminuição do teor de proteína bruta das rações, mas não houve interferência neste valor quando variada a concentração dos aminoácidos lisina e metionina.

\section{AGRADECIMENTOS}

À FAPEAM - Fundação de Amparo à Pesquisa do Estado do Amazonas, pelo apoio financeiro e a toda equipe do CPAQ-INPA.

\section{BIBLIOGRAFIA CITADA}

A.O.A.C. 1995. Association of Official Analytical Chemists. Official Methods of Analysis. 17a. ed. Arlington. 1141pp.

Ahmed, I.; Khan, M.A., 2004. Dietary lysine requirement of fingerling Indian major carp, Cirrhinus mrigala (Hamilton). Aquaculture, 235: 499-511.

Alceste, C.C.; Jory, D.E. 2000. Tilápia - Alternative protein sources in tilapia feed formulation. Aquaculture Manegement, 26 (4):713.

Aoki, H. Akimoto, A.; Watanabe, T. 2001. Periodical changes of plasma free amino acid levels and feed digesta in yellowtail after feeding non-fish meal diets with or without supplemental crystalline amino acids. Fisheries Science, 67: 614-618.

Carter, C.G.; Hauler, R.C. 2000. Fish meal replacement by plant meals in extruded feeds for Atlantic salmon, Salmo salar L. Aquaculture, 185: 299-311.

Chagas, E.C.; Lourenço, J.N.P.; Gomes, L.C.; Val, A.L. 2003. Desempenho e estado de saúde de tambaquis cultivados em tanques-rede sob diferentes densidades de estocagem. In: Urbinati, E.C.; Cyrino, J.E.P. (Eds.). XII Simpósio Brasileiro de Aqüicultura. Aquabio, Jaboticabal, SP. p. 83-93.

Chakraborty, S.C.; Ross, L.G.; Ross, B. 1992. The effect of dietary protein level and ration level on excretion of ammonia in common carp. Comp. Biochem. Physiol. 103A, 801-808.

Cheng, Z.J.; Hardy, R.W.; Ursy, J.L. 2003. Plant protein ingredients with lysine supplementation reduce dietary protein level in rainbow trout (Oncorhnchus mykiss) diets, and reduce ammonia nitrogen and soluble phosphorus excretion. Aquaculture, 218: 553-565.

Dabrowski, K.; Guderley, H. Intermediary metabolism. 2002. In: Halver, J.E.; Hardy, R. W. (Eds.) Fish Nutrition. 3 ed. Washington, D.C.: Academic Press. p. 309-365.

English, W.R.; Schwedler, T.E.; Dyck, L.A. 1993. Aphanizomenon flos-aquae, a toxic blue green alga in commercial channel catfish, Ictalurus punctatus, ponds: a case history. Journal of Applied Aquaculture, 3: 195-209.

Furuya, W. M. Silva L.C.; Neves, P.R.; Botaro, D.; Hayashi C.; Sakaguti, E. S.; Furuya, V.R.B. 2004b. Exigência de metionina + cistina para alevinos de tilápia do Nilo (Oreochromis niloticus). Ciência Rural, Santa Maria, 34(6): 1933-1937.
Furuya, W.M.; Botaro, D.; Neves, P.R.; Silva, L.C.R.; Hayashi, C. 2004a. Exigência de lisina pela Tilápia do Nilo (Oreochromis niloticus), na fase de terminação. Ciência Rural, 34 (5): 1571 1577.

Greenhouse, S.W.; Geisser, S. 1959. On methods in the analysis of profile data. Psychometrika, 24(2): 95-112.

Ismirño-Orbe, R.A.; Araújo-Lima, C.A.R.M.; Gomes, L.C. 2003. Excreção de amônia por tambaqui (Colossoma macropomum) de acordo com variações na temperatura da água e massa do peixe. Pesquisa Agropecuária Brasileira, 38(10):1243-1247.

Izel, A.C.U.; Melo, L.A.S. 2004. Criação de tambaqui (Colossoma macropomum) tanques escavados no Estado do Amazonas. Embrapa Amazônia Ocidental. Documentos, 32: 20.

Kaushik, S.J.; Cowey, C.B. 1990. Dietary factors affecting nitrogen excretion by fish. In: Cowey, C.B.; Cho, C.Y. (Eds.), Nutritional Strategies and Aquaculture Waste, Ontario, 5-8 June, University of Guelf, Canada. p. 3-19.

Melo, L.A.S.; Izel, A.C.U.; Rodrigues, F.M, 2001. Criação de tambaqui (Colossoma macropomum) em viveiros de argila/barragens no Estado do Amazonas. Manaus: Embrapa Amazônia Ocidental. Brasil. 30pp

NRC - National Research Council. 1993. Nutrient requirements of warmwater fishes and shellfishes. Washington: National Academy. 102pp.

Pezzato, L. E. 1997. O Estabelecimento das Exigências Nutricionais das Espécies de Peixes Cultivadas. In: Anais do Simpósio Sobre Manejo e Nutrição de Peixes. Piracicaba, SP.

Rodehutscord, M.; Borchert, F.; Gregus, Z.; Pack, M.; Pfeffer, E. 2000. Availability and utilization of free lysine in rainbow trout (Oncorhynchus mykiss). Effect of dietary crude protein level. Aquaculture, 187: 163-176.

Rollin, X.; Mambrini, M.; Abboudi, T. et al. 2003. The optimum dietary indispensable amino acid pattern for growing Atlantic salmon (Salmo salar L.) fry. British Journal of Nutrition, 90: 865-876

Ruchimat, T.; Masumoto, T.; Hosokawa, H.; Shimeno, S. 1997. Quantitative methionine requirement of yellowtail (Seriola quinqueradiata). Aquaculture, 150: 113-122.

Rychly, J. 1980. Nitrogen balance in trout: II. Nitrogen excretion and retention after feeding diets with varying protein and carbohydrate levels. Aquaculture, 20:343-350.

Storebakken, T.; Refstie, S.; Ruyter, B. 2000. Soy products as fat and protein sources in fish feeds for intensive aquaculture. In: Drackley, J.K. (Ed), Soy in Animal Nutrition. Fed Anim. Sci. Sco., Savoy, II, USA, p. 127-170.

Tantikitti, C.; March, B.E. 1995. Dynamics of plasma free amino acids in rainbow trout (Oncorhynchus mykiss) under variety of dietary conditions. Fish Physiology Biochemistry, 14: 179-194.

Thoman, E.S.; Davis, D.A.; Arnold, C.R. 1999. Evaluation of growout diets with varying protein and energy levels for red drum (Sciaenops ocellatus). Aquaculture, 176: 343-353.

Van Der Ploeg, M.; Tucker, C.S. 1994. Seasonal trends in flavor quality of channel catfish. Ictalurus punctatus, from commercial 
ponds in Mississippi. Journal of Applied Aquaculture, 3: 121140.

Viola, S.; Lahav, E. 1991. Effects of lysine supplementation in practical carp feeds on total protein sparing and reduction of pollution. Isr. J. Aquac, 43: 112-118.

Viola, S., Lahav, E., Angeoni, H., 1992. Reduction of feed protein levels and of nitrogenous $\mathrm{N}$-excretions by lysine supplementation in intensive carp culture. Aquat. Living Resour., 5: 277-285.

Walton, M.J.; Cowey, C.B.; Adron, J.W. 1984. The effect of dietary lysine levels on growth and metabolism of rainbow trout (Salmo gairdneri). Br. J. Nutr., 52: 115-122.
Westers, H. 2001. Production. In: Wedemeyer, G. A. (Ed.). Fish hatchery management. 2nd ed. Bethesda: American fisheries Society. p. 31-90.

Yamamoto, T.; Sugita, T.; Furuita, H. 2005. Essential amino acid supplementation to fish meal-based diets with low protin to energy ratios improves the protein utilization in juvenile rainbow trout Oncorhinchus mykiss. Aquaculture, 246(1-4): 379-391.

Recebido em 09/07/2007

Aceito em 18/03/2009 